\title{
DEVELOPMENT AND VALIDATION OF DESCRIPTORS FOR UNIVERSAL PROBLEM-ANALYSIS RUBRIC
}

\author{
Bahar Memarian and Susan McCahan \\ Department of Mechanical and Industrial Engineering, University of Toronto
}

\begin{abstract}
This paper describes the process for creating and validating descriptors for a universal problem-analysis rubric. Our objective is to create descriptors that provide effective feedback to students on assessments that have been designed to elicit the demonstration of metacognitive problem-analysis skills.

Building on previously tested and validated indicators as well as benchmarking descriptors from credible and cited rubrics (e.g. the VALUE rubrics), the descriptors were developed through decomposition of global outcome statements and expansion into separate dimensions. The descriptors were then iteratively revised through consultation with faculty experts who teach in fields where assessment of problem-analysis is common. This involved individual faculty and focus group sessions held with engineering faculty members.

The universal problem-analysis rubric created could serve as a resource for engineering faculty to accompany their problem-analysis learning activities (e.g. problem sets) and to elicit student work that is aligned with learning outcomes students need to demonstrate to fulfill CEAB assessment needs. They could also use them as an evaluation tool to increase consistency and reliability of evaluation especially in large classes with multiple assessors.
\end{abstract}

Keywords: Analytic Rubric, Performance-based rubric, Problem-analysis, Learning Outcomes, Assessment, Problem Solving

\section{INTRODUCTION}

The increasing focus on measuring learning outcomes to meet the requirements of accreditation (ABET, 2016; CEAB, 2016) and a general trend toward accountability in higher education have driven the need for competency based evaluation and assessment tools in university classrooms. Program level learning outcomes relate to employability skills on a broader multidisciplinary level (Riebe \& Jackson, 2014). As much of the engineering program is focused on teaching domain specific knowledge and principles, it is important to infuse the acquisition of high level engineering skills (e.g. problem-analysis) into this context. Analytic rubrics can assist in this process. Analytic rubrics provide a space to assess student performance, as well as provide feedback and direction on student metacognitive skills beyond the simple acquisition of content.

An analytic rubric is commonly created as a twodimensional table. Indicators, also called criteria, are in the first column specifying what we seek the students to demonstrate (learning outcomes). The column header row has the achievement levels, e.g., fails, below expectations, and so on. The performance of the student based on the achievement level and indicator is then described in each cell within the table and is called a descriptor. Descriptors could be further broken down into multiple sub-criteria which are referred to here as dimensions. When developing descriptors for an indicator, it is necessary to use consistent dimension areas across the performance levels to achieve parallelism. Additionally, the descriptor topics need to be relevant to their indicator to achieve alignment. Doing so can help in meeting the needs for criteria and content validity in assessment (Messick, 1994).

Among universal rubrics, one of the most widely used set is the VALUE rubrics. There are 16 VALUE rubrics that were developed by educational professionals across a wide variety of higher education institutions in an initiative sponsored by the Association of American Colleges and Universities (AAC\&U, 2009) The rubrics, however, similar to some rubrics developed by Canadian institutions (Univ. of Manitoba, 2015; Queen's Univ., 2017; Univ. of Guelph, 2012) describe student performance across different achievement levels at a paragraph level. This may make them difficult to follow and use for students and assessors as the descriptor criteria are grouped and described at an overall level.

The current project is part of the Learning Outcomes Assessment Consortium sponsored by the Higher Education Quality Council of Ontario (HEQCO). The goal is to develop analytic rubrics that detail the expected learning outcomes for five Canadian Engineering Accreditation Board (CEAB) graduate attributes at a level of granularity that provides the student with useable formative feedback. The areas in which we are developing rubrics are: investigation, problemanalysis, teamwork, communication, and design. The focus of this paper is on the development and validation of descriptors for problem-analysis rubric. 


\section{METHODS}

Review of relevant literature was initiated prior to the development of descriptors and continued throughout the process of descriptor creation. The indicators for this competency had been developed through previous work (McCahan et al., 2017). The dimensions were then identified in this current stage of the project through benchmarking and decomposing descriptor outcome statements from wellrecognized sources (AAC\&U, 2016; Woods et al., 2001; Woods et al, . 2002; GAC, 2012). For example, the problemsolving VALUE rubric presents the following high achieving descriptor for the indicator "Define the problem": "Demonstrates the ability to construct a clear and insightful problem statement with evidence of all relevant contextual factors" (AAC\&U, 2009). From this, we extracted "clarity" and "articulation" as two necessary dimensions for defining the problem. Benchmarking allowed us to identify additional dimensions that were not initially captured while ensuring the validity of the rubric was not altered. Examples of dimension topics created for the first of the eight constructs: Define and characterize the problem are shown in appendices (Table 1).

The second stage of the descriptor development was focused on mapping the descriptor topics across different performance levels. This involved using adjectives, adjectival phrases, adverbs and adverbial phrases that would best suit to the descriptor topic at hand (Figure 1). Combinations of qualitative and quantitative phrases were used to make the distinction between performance levels. Moreover, the descriptors for the fail level were categorized into two types: not demonstrated and miscomprehended. The two levels of fail did not have order of precedence. Rather, they are intended to provide more relevant insight and feedback to the two groups of underperforming students.

The developed descriptor dimensions were first revised with a faculty expert who teaches in fields where assessment of problem-analysis is common. The meetings with this faculty expert enabled thorough revision and addition of dimension topics. Second, focus group sessions were held with engineering faculty member groups and the alignment between descriptor and indicators as well as utility and application of rubric rows were reviewed for a revised rubric. A total of six faculty members reviewed and validated the problem-analysis rubric descriptors.

\section{RESULTS AND DISCUSSION}

The focus group sessions were useful in addressing points of confusion and misalignment between the indicators and the developed descriptors. The faculty members identified issues with the rubrics at a very general, overall level, issues with specific areas of the rubric, and suggestions for detailed word changes. For example, one issue identified with a specific rubric area was that the rubric should incorporate representations and models not only at the problem level but also at the solution level. An example given was adding data analysis, plots and charts to the solution process (e.g. 05A Review results relative to the problem defined). Regarding the levels, it was pointed out that some terms are difficult to assess and to place on a performance scale. For instance, it is difficult to determine which of the terms "inaccurately" or "vaguely" are worse when attributing to fail and below expectations performance levels. To address this, we reduced the use of these terms to the extent possible. Additionally, it was suggested that a three-level achievement scale (e.g. fails, meets, exceeds) may be more suitable because anything more granular adds to the difficulty of categorizing the work. Although this is a valid concern for summative purposes, the main intention of the developed rubric is for formative purposes, providing more detailed feedback to underperforming students on the steps they need to take to improve their performance. Therefore, we made the decision to stay with a four level structure.

A topic brought up by multiple faculty members was the general nature of the adverbs used in distinguishing between performance levels, i.e., that the adverbs can be vague leading to confusion. Because the developed universal rubrics are intended to present learning outcomes and associated criterion at a high level (engineering program), we needed to use general terms. However, in the validation sessions we encouraged the use of anchors and exemplars (e.g. anchors to define and differentiate between accuracy and precision in identifying sources of error), drawn from the class where the rubric is deployed. As well we encouraged more use of quantitative performance level identifiers (e.g. provides three versus two sources etc.) when a faculty member employees the rubric in a specific course. We noted the concern, and will include this kind of advice for customizing the rubric in any accompanying guide that is developed for using the tool.

There were also suggestions to make the rubric rows more specific to a particular type of problem. For example, a faculty member suggested the addition of an indicator row regarding steady state problems which is commonly seen in engineering courses such as systems theory and thermodynamics. In addition, while the universal problemanalysis rubric is based on problem-analysis indicators from the literature, some faculty members believed the rubrics would be best suited for open-ended questions, projects and design based courses. It was also suggested to use such rubrics for graduate level courses more often, where students' analytical research skills become more prominent as compared to knowledge of facts and principles. The authors agree that the developed rubric could be deployed in a wider range of courses than only undergraduate, "fact and principle" style courses, and that the rubric can have additional rows to support outcomes specific to a course. However, for purposes of the work here, we focused on undergraduate courses and generalizable outcomes.

A problem-analysis rubric with eight constructs each containing a list of indicators and associated descriptor 
dimensions were developed. A full version of the rubric is available at https://sites.google.com/site/uoftlearningoutcomesproject. The aim of the study was to make use of and include information from descriptors that are known to have validity and reliability in literature, but we also wanted to see if we could make changes to such descriptors to further improve their usability. Some features that made the developed rubric different from existing rubrics that are similar in nature and are centered on competency based learning outcomes (e.g. VALUE) are discussed here. Additionally, sample descriptor rows developed for the problem-analysis rubric are shown in appendices (Table 2).

Distinguishing between types of underachieving (fail level) student performance: We found it important to distinguish between students who miscomprehend a concept substantially and those that did not demonstrate the learning outcome sufficiently. This is because the group that miscomprehended the concept may be students who completed the work but demonstrate a misconception so the feedback should be around correcting the misconception. The group that failed to demonstrate, however, has not completed the work necessary to judge their understanding or ability. For this group, feedback should be around the need to complete their work, which is a different type of intervention. In typical rubrics, the lack of distinguishing between the two groups confounds the feedback to these students who are most in need of assistance.

Increasing the level of detail: Most existing rubrics are designed to be short and commonly fit on one page. This rubric, on the other hand, contained several constructs each grouping a list of indicators and associated descriptors, with indicators sometimes sharing similar context. For instance, in construct 01 Define and characterize the problem, there are indicators such as: $01 \mathrm{~F}$ Identify known information; $01 \mathrm{H}$ Identify relevant models, concepts, or theories; $01 \mathrm{~K}$ Reformulate a problem in terms of relevant models, concepts or theories. Even though the indicators may seem similar in nature - that is identification of information (known and unknown) from a given problem - their associated descriptors are different in context and level of detail (i.e. number and nature of dimensions). The rationale is that the developed rubric can serve as a bank for instructors to select and choose the indicator rows best aligned to their specific learning activities. As such having indicators that are similar in nature with varying level of detail and performance criteria will enable instructors to select and use indicators for different types of learning activities (e.g. problem set, project) that best align with the intended learning goals. Hence evaluating similar learning outcomes across different artifacts provides multiple opportunities for students to demonstrate their level of understanding. This way instructors could also examine if different levels of performance are seen with different types of learning artifacts (e.g. better performance on a project versus a test).
Ease of use: Chunking descriptors into dimensions and point form comments are more readable than paragraphs. This is an assumption which we are interested in testing in the future. A paragraph may fail to separate and identify distinct factors that together constitute achievement of a learning outcome at a certain performance level. As such we have used checkboxes and point form criteria to list independent dimensions within a descriptor cell to provide more granular feedback to the student.

More granular criterion-based feedback: Similar graduate attribute rubrics provide student performance at an overall (paragraph) level for three to five performance levels. The use of the developed rubrics enables assessors to provide more specific criterion-based feedback by looking at dimension areas. An assessor can provide different feedback and ratings for dimensions of the same indicator independently, not needing to average out the performance of a student for an indicator.

Even though rubrics could improve student understanding and alleviate differences between assessors, it is important to keep in mind the situational and confounding factors that could affect the development and use of such rubrics. One main factor is the interfering effect of summative feedback and norm-based assessment. Norm-based assessment assumes half of the student population for any given class size will fail or receive a lower mark than the other half. With a normally distributed student performance perspective, the assessor's attention thus may be focused on ranking students rather than seeing how well an individual student has achieved the learning objectives. This approach in turn brings in a competitive, minimally cooperative climate to the assessment environment. Rubrics are best used in a criteria-based schema, and the use of a rubric can encourage the individual assessment of students. So the student is evaluated against the rubric not ranked in the class.

Another factor impeding the effective use of rubrics the alignment with the assessment activity. To be effective the instructor must select an assessment activity that aligns well with the intended learning outcomes, provides instructions (i.e. an elicitation of a student performance) that is clear, and selects indicator rows that are aligned well with the assessment. Any misstep in this alignment process can result in a poor rubric; not because the rubric is inherently poor, but because it is poorly utilized.

\section{CONCLUSIONS}

The use of formative, feedback based interventions such as the developed problem-analysis analytic rubric could support improvements in teaching, learning, and assessment as it has the following features:

1. It does not threaten assessment's content validity as it is benchmarked from credible rubrics.

2. It is universal (i.e. generalizable), meaning it is not restricted to a specific artifact (e.g. assignment) or certain type 
of question. Any learning activity that requires evaluation of problem-analysis skills could make use of this rubric.

3. It is intended for formative purposes. While such rubrics could also be used for summative purposes, they are mainly used to inform and guide students on adjusting their learning through a course.

4. It is customizable. Based on the learning objectives, length, and time of a learning activity, the indicator rows can be removed or simplified. Additionally, depending on the performances of students in a class, some performance level columns can be removed or merged with adjacent columns.

5. It can be contextualized. While the developed rubric is centered on general meta-cognitive problem-analysis skills, the problem-analysis indicators and descriptors can be put in a specific context by adding domain specific theory and skills.

As outlined in the literature (Stevens \& Levi, 2005) rubrics (1) provide a task description; (2) develop a scale for evaluation; (3) develop dimensions of the task necessary for success; and (4) provide a description of the dimensions relative to the scale being used. Contrary to many of the rubrics available which outline student performance at a paragraph level, the design of this rubric decomposes specific criteria into granular dimensions. It could thus better meet the intentions of rubrics as a formative feedback tool.

When the criteria for student performance are not explicitly classified and paired with level of student performance, different assessors with different perceptions and standards for a solution to a problem may approach and grade the same student artifact quite differently. The importance of descriptors for each achievement level therefore becomes apparent as indicators by themselves only provide areas where we want to assess students, but reveal little information on how to reliably distinguish and set apart different student performances. As part of the future work and to further validate the problem-analysis usability, we will be shadow testing the developed rubric with a group of teaching assistants on problem sets and assignments where student work had been previously graded. Through this process, the usability, assessor perceptions, and inter-rater reliability of universal problem-analysis rubric will be examined

\section{ACKNOWLEDGEMENT}

This research study was made possible by the funding of Higher Education Quality Council of Ontario (HEQCO) Contract \#12/13RFP-006-06. For more information on HEQCO's Learning Outcomes Assessment Consortium, please visit

http://www.heqco.ca/enca/OurPriorities/LearningOutcomes/P ages/AssessmentConsortium.aspx.

In addition, the authors of this paper would like to thank the engineering faculty members in the Faculty of Applied Science and Engineering, University of Toronto who participated in this work for their contribution.

\section{REFERENCES}

AAC\&U. (2009). Problem Solving VALUE Rubric. Retrieved January 1, 2017, from http://www.aacu.org/valuerubrics

ABET. (2016). Criteria for accrediting engineering programs. Retrieved from http://www.abet.org/accreditation/accreditationcriteria/criteria-for-accrediting-engineering-programs2016-2017/

CEAB. (2016). Engineering Instruction and Accreditation Graduate Attributes. Retrieved from https:/engineerscanada.ca/sites/default/files/GraduateAttributes.pdf

GAC. (2012). Internal Document on the development of the graduate attributes process University of Toronto, Faculty of Applied Science and Engineering.

McCahan, S; Beach, D; Memarian, B; Lesmond, G; Dawe, N. (2017). UofT Learning Outcomes Project. Retrieved from https://sites.google.com/site/uoftlearningoutcomesproje ct/

Messick, S. (1994). Validity of psychological assessment: Validation of inferences from persons' responses and performances as scientific inquiry into score meaning. ETS Research Report Series.

Queen's University Learning Outcomes Project. (2017). Retrieved from http://www.queensu.ca/qloa/assessmenttools/value-rubrics-0

Riebe, L., \& Jackson, D. (2014). The Use of Rubrics in Benchmarking and Assessing Employability Skills. Journal of Management Education, 38(3), 319-344.

University of Guelph Learning Outcomes. (2012). Retrieved from http://www.uoguelph.ca/vpacademic/avpa/outcomes/

University of Manitoba Graduate Attribute Rubrics. (2015). Retrieved from https://goo.gl/dMngLp

Woods, D. R., Kourti, T., Wood, P. E., Sheardown, H., Crowe, C. M., \& Dickson, J. M. (2001). Assessing Problem-Solving Skills Part 1: The Context for Assessment. Chicago: Chemical Engineering Education.

Woods, D. R., Kourti, T., Wood, P. E., Sheardown, H., Crowe, C. M., \& Dickson, J. M. (2002). Assessing Problem Solving Skills Part 2: Assessing the Process of Problem Solving. Chemical Engineering Education. 


\section{APPENDICES}

Table 1: Development of descriptor topics for first construct of problem-analysis rubric:

Define and characterize the problem

\begin{tabular}{|c|c|}
\hline Indicator & Descriptor Topic(s) \\
\hline 01A Distinguishing a problem from an example & $\begin{array}{l}\text { Recognizing an example and a problem in its original } \\
\text { context }\end{array}$ \\
\hline 01B State a problem in their own words & Depth and quality of reworded problem \\
\hline \multirow{2}{*}{$01 \mathrm{C}$ State and assess primary problem goal(s) } & Connection of goals to known information \\
\hline & Clarity and attainment level of goals \\
\hline \multirow{3}{*}{$\begin{array}{l}\text { 01D Characterize problem types (e.g. simple vs. } \\
\text { complex, open-ended vs. closed-ended, determinate vs. } \\
\text { indeterminate) }\end{array}$} & Distinguishing between different types of problems \\
\hline & Providing examples of each problem \\
\hline & Clarity and relevancy of examples to each problem \\
\hline \multirow[t]{3}{*}{ 01E Describe the causes of the problem and its effects } & Relevancy \\
\hline & Precision \\
\hline & Clarity \\
\hline \multirow[t]{2}{*}{ 01F Identify known information } & Identification of known information \\
\hline & $\begin{array}{l}\text { Accuracy and precision of known information } \\
\text { identified }\end{array}$ \\
\hline \multirow{3}{*}{$\begin{array}{l}01 \mathrm{G} \text { Construct a problem representation (abstract, } \\
\text { visual, mathematical, or otherwise) }\end{array}$} & Representation of problem with a particular model \\
\hline & Accuracy of particular model \\
\hline & $\begin{array}{l}\text { Use of relevant and disciplinary standards for } \\
\text { representation of particular model }\end{array}$ \\
\hline 01H Identify relevant models, concepts, or theories & $\begin{array}{l}\text { Identification of relevant models, concepts and/or } \\
\text { theories }\end{array}$ \\
\hline \multirow{3}{*}{$\begin{array}{l}\text { 01I Identify relevant assumptions, biases, or problem- } \\
\text { solving barriers }\end{array}$} & Depth \\
\hline & Precision \\
\hline & Accuracy \\
\hline 01J Recognize unknown information & Degree in which unknown information is recognized \\
\hline \multirow{2}{*}{$\begin{array}{l}01 \mathrm{~K} \text { Reformulate a problem (goals, information, } \\
\text { assumptions) in terms of relevant models, concepts or } \\
\text { theories }\end{array}$} & Accuracy of reformulated problem \\
\hline & Relevant models, concepts, or theories used \\
\hline \multirow{2}{*}{$\begin{array}{l}\text { 01L Formulate sub goals and measurable assessment } \\
\text { criteria }\end{array}$} & Alignment of sub goals with primary goal \\
\hline & Measurable sub goals \\
\hline
\end{tabular}

$\left.\left.\left.\left.\sum \begin{array}{c|c|c|c|c|c|}\multicolumn{2}{c}{\text { Fails }} & \text { Fails } & \text { Below } \\ \text { Presented } & \begin{array}{c}\text { Incorrect or } \\ \text { irrelevant work } \\ \text { presented }\end{array}\end{array}\right\rangle \begin{array}{c}\text { Minimal work } \\ \text { presented }\end{array}\right\rangle \begin{array}{c}\text { Adequate work } \\ \text { presented }\end{array}\right\rangle \begin{array}{c}\text { Comprehensive } \\ \text { work presented }\end{array}\right\rangle$

Figure 1: Distinguishing between performance levels using adjectives, adjectival phrases, adverbs and adverbial phrases. The two levels of fail do not have order of precedence. 
Table 2: Sample descriptor rows developed for the problem-analysis rubric. Terminology related to rubric shown with arrows.

\begin{tabular}{|c|c|c|c|c|c|}
\hline Performance Levels $\rightarrow$ & $\begin{array}{l}\text { Fails } \\
\text { (Not Demonstrated) }\end{array}$ & Fails (Miscomprehended) & Below & Meets & Exceeds \\
\hline \multicolumn{6}{|c|}{01 Define and characterize the problem $\leftarrow$ (Construct for list of Indicators listed numerically) } \\
\hline $\begin{array}{l}\text { Indicators (assessment } \\
\text { criteria) listed } \\
\text { alphabetically } \downarrow\end{array}$ & \multicolumn{5}{|c|}{$\begin{array}{l}\text { Descriptor cells with dimensions (checkboxes) } \rightarrow \\
\downarrow\end{array}$} \\
\hline $\begin{array}{l}\text { 01E Describe the causes of } \\
\text { the problem and its effects }\end{array}$ & $\begin{array}{l}\text { Causes and effects are: } \\
\square \text { Not provided }\end{array}$ & $\begin{array}{l}\text { Causes and effects are: } \\
\square \text { Not related to the } \\
\text { problem }\end{array}$ & $\begin{array}{l}\text { Causes and effects are: } \\
\square \text { Vague } \\
\square \text { Imprecise } \\
\square \text { Not clearly related to the } \\
\text { problem }\end{array}$ & $\begin{array}{l}\text { Key causes and effects are: } \\
\square \text { On point } \\
\square \text { Precise } \\
\square \text { Clearly related to the } \\
\text { problem }\end{array}$ & $\begin{array}{l}\text { Key causes and effects are: } \\
\square \text { Insightful } \\
\square \text { Precise } \\
\square \text { Explicitly related to the } \\
\text { problem }\end{array}$ \\
\hline $\begin{array}{l}\text { 01G Construct a problem } \\
\text { representation (abstract, } \\
\text { visual, mathematical, or } \\
\text { otherwise) }\end{array}$ & $\begin{array}{l}\text { The problem is not } \\
\text { represented with a } \\
\text { model }\end{array}$ & $\begin{array}{l}\square \text { The problem is } \\
\text { improperly represented } \\
\text { with a model } \\
\square \text { The problem is } \\
\text { represented with an } \\
\text { inaccurate model } \\
\square \text { Uses irrelevant } \\
\text { disciplinary standards for } \\
\text { representation }\end{array}$ & $\begin{array}{l}\square \text { The problem is minimally } \\
\text { represented with a model } \\
\square \text { The problem is represented } \\
\text { with significant level of error } \\
\square \text { Uses irrelevant disciplinary } \\
\text { standards for representation }\end{array}$ & $\begin{array}{l}\square \text { The problem is } \\
\text { adequately represented with } \\
\text { a particular model } \\
\square \text { The problem is } \\
\text { represented with a } \\
\text { reasonably accurate model } \\
\square \text { Uses relevant disciplinary } \\
\text { standards for representation }\end{array}$ & $\begin{array}{l}\square \text { The problem is fully } \\
\text { represented with a } \\
\text { particular model } \\
\square \text { The problem is } \\
\text { represented with an } \\
\text { accurate model } \\
\square \text { Uses appropriate } \\
\text { disciplinary standards for } \\
\text { representation }\end{array}$ \\
\hline \multicolumn{6}{|c|}{03 Propose solution process } \\
\hline $\begin{array}{l}\text { 03A Plan a systematic } \\
\text { solution process (i.e., } \\
\text { identifies measurable tasks } \\
\text { that support sub goals) }\end{array}$ & $\begin{array}{l}\square \text { Tasks not specified } \\
\square \text { No plan presented }\end{array}$ & $\begin{array}{l}\text { Tasks specified are: } \\
\square \text { Flawed plan presented } \\
\square \text { Unclear } \\
\square \text { Do not support sub } \\
\text { goals }\end{array}$ & $\begin{array}{l}\text { Tasks specified are } \\
\square \text { Plan is marginal } \\
\square \text { Somewhat clear } \\
\square \text { Minimally support sub } \\
\text { goals }\end{array}$ & $\begin{array}{l}\text { Tasks specified are: } \\
\square \text { Effective plan is } \\
\text { presented } \\
\square \text { Reasonably clear } \\
\square \text { Mostly support sub goals } \\
\end{array}$ & $\begin{array}{l}\text { Tasks specified are: } \\
\square \text { Plan is thoroughly } \\
\text { presented } \\
\square \text { Clear and succinct } \\
\square \text { Fully support sub goals }\end{array}$ \\
\hline \multicolumn{6}{|l|}{04 Implement a solution } \\
\hline $\begin{array}{l}\text { 04C Recognize and } \\
\text { accommodate for } \\
\text { unforeseen constraints, or } \\
\text { unattainable sub goals, } \\
\text { during execution }\end{array}$ & $\begin{array}{l}\square \text { No recognition and } \\
\text { accommodation }\end{array}$ & $\begin{array}{l}\square \text { Incorrect recognition } \\
\square \text { Incorrect } \\
\text { accommodation }\end{array}$ & $\begin{array}{l}\square \text { Partial or little recognition } \\
\square \text { Errors in the } \\
\text { accommodation }\end{array}$ & $\begin{array}{l}\square \text { Complete recognition } \\
\square \text { Routine accommodation }\end{array}$ & $\begin{array}{l}\square \text { Full recognition } \\
\square \text { Creative and effective } \\
\text { accommodation }\end{array}$ \\
\hline
\end{tabular}

